\title{
The Role of Rehabilitation Specialists in Canadian NICUs: A 21st Century Perspective
}

Pamela Borges Nery, Laurie Snider, José Simon Camelo Junior, Zachary Boychuck, Fatima Khodary, Jessica Goldschleger \& Annette Majnemer

To cite this article: Pamela Borges Nery, Laurie Snider, José Simon Camelo Junior, Zachary Boychuck, Fatima Khodary, Jessica Goldschleger \& Annette Majnemer (2019) The Role of Rehabilitation Specialists in Canadian NICUs: A 21st Century Perspective, Physical \& Occupational Therapy In Pediatrics, 39:1, 33-47, DOI: 10.1080/01942638.2018.1490846

To link to this article: https://doi.org/10.1080/01942638.2018.1490846

曲 Published online: 28 Sep 2018.

Submit your article to this journal $\pi$

Lll Article views: 703

Q View related articles $\longleftarrow$

View Crossmark data $־$

4 Citing articles: 4 View citing articles 


\title{
The Role of Rehabilitation Specialists in Canadian NICUs: A 21st Century Perspective
}

\author{
Pamela Borges Nery ${ }^{\mathrm{a}, \mathrm{b}}$, Laurie Snider ${ }^{\mathrm{c}, \mathrm{d}, \mathrm{e}}$, José Simon Camelo Junior ${ }^{\mathrm{a}}$, \\ Zachary Boychuck ${ }^{c, d, e}$, Fatima Khodary ${ }^{c}$, Jessica Goldschleger ${ }^{c}$, and \\ Annette Majnemer ${ }^{\mathrm{c}, \mathrm{d}, \mathrm{e}}$

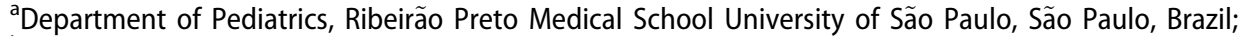 \\ ${ }^{b}$ Centro Universitário Estácio de Ribeirão Preto, Ribeirão Preto, Brazil; 'School of Physical \& \\ Occupational Therapy, McGill University, Montreal, QC, Canada; ${ }^{\mathrm{d}}$ Centre for Interdisciplinary Research in

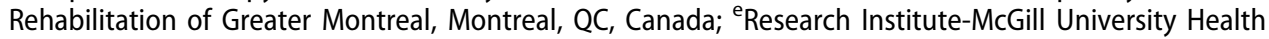 \\ Centre and Montreal Children's Hospital, Montreal, QC, Canada
}

\begin{abstract}
Rehabilitation specialists are an integral part of the team in the neonatal intensive care unit (NICU). New approaches to rehabilitation practice in the NICU have evolved over the past decade that aim to promote child health and development. Aims: The aim of this study was to describe the current roles of the occupational therapist (OT), physical therapist (PT) and speech-language pathologist (SLP) in Canadian NICUs as compared to the roles documented in an earlier national survey conducted 15 years ago. Methods: A telephone survey was conducted across Canadian NICUs and each telephone interview was recorded by a research assistant. In total, 42 questionnaires were completed across 25 health care institutions. Results: Eighty percent of the PT, $93.7 \%$ of OT and $50 \%$ of SLP provided direct services to neonates in the NICU. The results demonstrated that the therapists were involved with case discussion (85.7\%), decision-making $(97.6 \%)$, referrals to other services (97.6\%) and discharge planning (97.6\%). Splinting (87.5\%) and feeding (100\%) were most often carried out by OT, whereas chest physiotherapy (65\%) and range of motion (100\%) were predominantly provided by PT. Changes in the role of rehabilitation specialists over the last decade predominantly included enhanced collaboration with the NICU team, more frequent use of standardized outcome measures and use of interventions supported by evidence. Conclusion: In comparison with results of the previous survey of rehabilitation practices in Canadian NICUs, rehabilitation specialists now have more dedicated time in the NICU and more frequently use standardized measures and apply interventions that are supported by recent scientific studies.
\end{abstract}

\section{ARTICLE HISTORY}

Received 20 April 2017

Accepted 5 June 2018

\section{KEYWORDS}

Neonatal intensive care unit; occupational therapy; physical therapy; speechlanguage pathology; rehabilitation services

\section{Introduction}

Newborns born critically ill, whether full term or preterm, are at high risk for disability (Als et al., 2004). Although recent advances in technological development and medical

CONTACT Laurie Snider laurie.snider@mcgill.ca E School of Physical \& Occupational Therapy, McGill University, Montreal, QC, Canada.

This article has been republished with minor changes. These changes do not impact the academic content of the article. 
and surgical practices in tertiary level neonatal intensive care units (NICUs) have augmented the survival rates of fragile neonates (Atun-Einy \& Scher, 2008), a great number of developmental morbidities persist for NICU survivors (Beck et al., 2010). For rehabilitation therapists (i.e. occupational therapists [OTs], physical therapists [PTs], and speech-language pathologists [SLPs]) specializing in the care of neonates in this unique care environment, a multi-stakeholder model of practice involving the child, family, and health professionals is expected to enhance competence (Barbosa, 2013; Limperopoulos \& Majnemer, 2002). Interventions for the high-risk neonate require specialized skills and knowledge in multiple practice components (Legendre et al., 2011). For example, during lengthy NICU hospitalizations rehabilitation specialists may utilize multiple therapeutic intervention approaches such as positioning techniques, sensorimotor stimulation, and behavioral strategies to prevent or minimize impairments in motor, behavioral, cognitive, and oral motor development (Mahoney \& Cohen, 2005).

As members of the NICU team, rehabilitation specialists provide complementary assessment and intervention strategies which are designed to minimize sensory and neurobehavioral deficits, prevent musculoskeletal contractures and deformities, optimize safe and efficient oral feeding, and promote the self-regulation abilities of the newborn (King et al., 2008). Moreover, developmental surveillance contributes to the early identification of those infants most at risk for developmental disability and should incorporate strategies about clinical monitoring and referral, health promotion, educational activities, and collaboration in research (Limperopoulos \& Majnemer, 2002; Symington \& Pinelli, 2006).

In an earlier survey about the role of rehabilitation specialists in all Canadian NICUs, Limperopoulos and Majnemer (2002) identified knowledge gaps and a need for therapists to have access to outcomes-based research that described the effectiveness of OT, PT, and SLP interventions in the NICU, so as to inform best clinical practices. Although services, when provided, were very comprehensive, assessments used were often not standardized measures and interventions were not adequately supported by scientific evidence. In addition, the authors stated that an optimal rehabilitation practice in the NICU should involve a dynamic exchange of information across health care disciplines, a pursuit of continuing education opportunities and ideally, involvement in research to ensure that current clinical practice was aligned with best practice (Limperopoulos \& Majnemer, 2002).

Research over the last decade has supported the competencies of OT, PT, and SLP in the NICU through guidelines and evidence-based standards of practice published by researchers and the respective professional organizations (ASHA, 2004; Atun-Einy \& Scher, 2008; Campbell, 2013; Chiarello \& Effgen, 2006; O’Connor \& Pettigrew, 2009; Sweeney et al., 2009). Perceived barriers, such as insufficient time, costs of continuing education, conflicting evidence, and lack of supervisory support may prevent the successful implementation of evidence-based practice by SLTs (ASHA, 2004). Indeed these barriers to knowledge translation are common to most health professionals. Furthermore, role responsibilities may vary from institution to institution as related to the interdisciplinary approach, the background and specialized training of each professional, and institution-specific policies (Aita \& Snider, 2003; Barbosa, 2013; Byrne \& Campbell, 2013).

New approaches to rehabilitation practice in the NICU that promote the health of the newborn and his/her family have evolved over the past 10-15years 
(Adams-Chapman, 2006; Aita \& Snider, 2003; Als \& McAnulty, 2011; Constantinou et al., 2005). The current literature describes a number of standardized, reliable, and valid neonatal and infant assessments of movement and neurobehavioral status such as the Neurobehavioral Assessment of the Preterm Infant (Harijan et al., 2012; Korner, Thom \& Constantinou, 2000), Test of Infant Motor Performance (TIMP; Campbell, Kolobe, Osten, Lenke, \& Girolami, 1995; Majnemer \& Snider, 2005; Snider, Majnemer, Mazer, Campbell, \& Bos, 2008), and the General Movements Assessment of Infants (Chandler, Andrews, Swanson, \& Larson, 1980; Darsaklis, Snider, Majnemer, \& Mazer, 2011 Prechtl, 2001) Furthermore, effective intervention approaches such as individualized developmental care and kangaroo care (Als \& McAnulty, 2011) to improve developmental outcomes, as well as oral-motor interventions to enhance feeding safety and efficiency (Fucile et al., 2011; Garber, 2013) are examples of current evidence-based practices that promote healthy development for NICU survivors. The NICU care path for PTs and the NICU discharge path for parents are examples of evidence-based guidelines where the focus of care is family-centered (Campbell, 2013; Garber, 2013; Goldstein, 2013). However, it remains to be determined if use of standardized measures and evaluation approaches, evidence-based interventions, and practice guidelines are actually utilized as part of current Canadian practice.

The main objective of this study was to describe the current roles and practices of rehabilitation specialists (OT, PT, and SLP) in the NICUs across Canada. A secondary objective was to compare these roles and practices to those documented 15 years ago (Limperopoulos \& Majnemer, 2002). Specifically, we hypothesized that rehabilitation specialists would have more dedicated time in the NICU, be more likely to use psychometrically sound standardized measures, and apply intervention strategies that are supported by recent scientific studies.

\section{Methods}

\section{Participants}

The invitation to participate in the national survey was extended to all departments providing rehabilitation services in all Canadian health care institutions with Level III NICUs $(n=31)$. However, only 25 institutions responded to the invitation (response rate: $80.6 \%[n=25]$ ). These units are considered vital for survival of critically ill full term and preterm infants, who represent a group at high risk for acute developmental challenges warranting the need for acute rehabilitation services. The inclusion criteria for the invitation to participate in the telephone survey were the rehabilitation professionals (i.e. OT, PT, and SLP), who provided any type of rehabilitation service (direct and/or consultative) to the Level III NICUs in their institution. Academic students of OT, PT, and SLP were excluded.

\section{Procedures}

A telephone survey was conducted between April and June 2014 to describe the current roles of rehabilitation specialists (OT, PT, and SLP) in all Canadian health care institutions with tertiary level NICUs $(n=31$ total). Using the Canadian registry of NICUs 
(www.canadianneonatalnetwork.org), three trained research assistants contacted the rehabilitation service departments of each institution by telephone and determined if there was an OT, PT, and/or SLP providing services to their NICU.

The procedure for training the research assistants included: an explanation of the objectives of the survey, discussion about how to identify the institution-specific professionals in the NICU, familiarization with the questionnaire, and clarification of the questions for the interviews. Once participants were identified, the rehabilitation professionals signed the consent form agreeing to participate in the research and sent it back by e-mail to the research assistant or to the principal investigator. After that, a telephone interview was scheduled at the convenience of the rehabilitation professional, and the survey was completed. The time spent on the telephone for each interview was approximately $10-20 \mathrm{~min}$.

\section{Telephone survey questionnaire}

The descriptive questionnaire developed by Limperopoulos and Majnemer (2002) that was previously used to collect data about current practices of rehabilitation specialists in NICU was used to conduct the telephone interviews. This enabled us to directly compare current practice profiles with those collected 15 years prior to our data collection, in 1999. The questions and topics were based on literature evidence regarding practice and role issues outlined as relevant to rehabilitation services in the NICU. According to the previous survey, the questionnaire content was reviewed by three neonatal rehabilitation specialists. In terms of applicability, the questionnaire was analyzed by epidemiologists and methodologists on the team, reviewed for content validity by three rehabilitation specialists who worked in the NICU, and field-tested in one institution. The previous survey was not altered so that direct comparisons could be made.

The questionnaire was divided into three sections and contained 13 questions. The first section contained general information such as years of practice in the NICU, experience, continuing education, training activities, and educational level. In the second section, the questions were based on the type of rehabilitation services offered in the NICU (e.g. provision of education for parents and families admitted to the NICU), infant assessments used, therapeutic interventions, and participation in research projects and in meetings about ethical decisions. The third section contained information about the time spent by the rehabilitation professional in the NICU, type of hospital setting (e.g. pediatric hospital, general hospital with pediatric wards, or adult hospital with NICU), type of population, type of intensive care unit (e.g. in-born, out-born, and mixed), and number of beds. The questions of the survey were presented in a multiple-choice format or in a categorical format (i.e. yes-no responses). An important open-ended question was added to the present survey to verify the opinion of the rehabilitation specialists about what they perceived had changed in terms of their role in the last decade.

\section{Data analysis}

The answers were structured in categorical thematic format. All answers were recorded and then double entered manually into a database. Responses were coded and tabulated in a spreadsheet in Excel format. Discrete variables were analyzed by frequency analyses 
Table 1. Diagnoses Seen by Rehabilitation Specialists in NICU.

\begin{tabular}{lccc}
\hline Diagnosis & OT (\%) & PT (\%) & SLP (\%) \\
\hline & $N=16$ & $N=20$ & $N=6$ \\
CNS disorders & 100 & 100 & 100 \\
Prematurity & 100 & 95 & 100 \\
Syndromes & 100 & 100 & 100 \\
Respiratory & 87.5 & 90 & 100 \\
Cardiac & 93.8 & 85 & 66.7 \\
Orthopedic & 87.5 & 95 & 16.7 \\
\hline
\end{tabular}

Note. $\mathrm{CNS}=$ central neurologic system, OT = occupational therapist, $\mathrm{PT}=$ physical therapist, $\mathrm{SLP}=$ speech language therapist, $\%=$ percentage.

and proportions, and continuous variables were analyzed by means and standard deviations. To verify the relationship between availability of rehabilitation professional and type of intervention, the Fisher Exact test was conducted. Statistical package for the Social Science - SPSS Version 17.0 (SPSS Inc, Chicago, IL, USA) was used for data analysis. The open answers were recorded and typed verbatim by the principal researcher $(\mathrm{PBN})$. A descriptive strategy was used to analyze the open-ended responses to the final question. These open responses were described by clustering thematic areas (e.g. collaboration with other rehabilitation specialists who work in the NICU, type of standardized assessment used in the NICU, other type of interventions provided in the NICU, and opinion about changes in the NICU over the last decade).

\section{Results}

\section{Group characteristics}

Among the 25 institutions which responded to the questionnaires, six provided no rehabilitation specialist coverage $(6 / 25 ; 24 \%)$, compared to $6 / 38(16 \%)$ in the last survey. Among the 19 institutions with NICU rehabilitation specialist coverage, most were pediatric hospitals (8/19: 42.1\%), followed by general hospitals (7/19: 36.8\%) and adult hospitals (4/19: $21 \%)$. The nursery types were in-born (2/19: 10.5\%), out-born (4/19: $21 \%$ ), and mixed (13/19: 68.4\%). Since the previous survey, the number of NICU beds in each setting had increased, ranging from 7 to 65 (mean: $38.9 \pm 17.1$ ) compared to the previous study, 5 to54 (mean: $23.7 \pm 12.4$ ).

\section{Rehabilitation services offered}

A total of 42 rehabilitation specialists responded to the questionnaire (PT: 20/42, 47.6\%; OT: $16 / 42,38 \%$; and SLP: $6 / 42,14.2 \%)$. Of these, the majority of OTs (15/16: $94 \%)$ and PTs (17/20: 85\%) provided weekly services in their NICUs, whereas fewer SLP (3/6: $50 \%)$ provided this level of coverage. The mean number of hours per week spent by each professional in the NICU (OT: $21.2 \pm 9.9 \mathrm{~h}$, range: $2.0-35.0$; PT: $20.3 \pm 10.9 \mathrm{~h}$, range: 2.0-40.0; and SLP: $20.5 \pm 10.5 \mathrm{~h}$, range: $8.5-28.0$ ) had increased compared to the previous survey (OT: $16.5 \pm 11.1 \mathrm{~h}, \mathrm{PT}$ : $13.2 \pm 12.3$, and SLP: $2.5 \pm 0.7$ ). The results of the current survey showed a marked increase in the time spent by SLP on the unit. Current results also showed that 11 NICUs had only one rehabilitation specialist. Of these, $54.5 \%$ of OTs (6/11) was the sole therapist in the NICU as compared to $45.4 \%$ of PT 
Table 2. Standardized Assessments Used by Rehabilitation Specialists in the NICU.

\begin{tabular}{|c|c|c|c|}
\hline Standardized assessments & $\begin{array}{l}\text { OT (\%) } \\
N=7\end{array}$ & $\begin{array}{l}\text { PT (\%) } \\
N=15\end{array}$ & $\begin{array}{c}\text { SLP (\%) } \\
N=2\end{array}$ \\
\hline Amiel-Tison (1968) & $28.6 \%$ & - & - \\
\hline $\begin{array}{l}\text { AIMS (Piper, Pinnell, Darrah, } \\
\text { Maguire, \& Byrne, 1991) }\end{array}$ & - & $33.3 \%$ & - \\
\hline TIMP (Campbell et al., 1995) & $42.8 \%$ & $66.6 \%$ & - \\
\hline $\begin{array}{l}\text { Rossetti Infant-Toddler } \\
\quad \text { Language Scale } \\
\text { (Rossetti, 1990) }\end{array}$ & - & - & $100 \%$ \\
\hline Bayley Scale (Bayley, 1993) & - & $6.7 \%$ & - \\
\hline MAI (Larson, 1980) & - & $6.7 \%$ & - \\
\hline NNNS (Lester \& Tronick, 2004) & $14.3 \%$ & - & - \\
\hline $\begin{array}{l}\text { Neurological assessment of } \\
\text { the preterm and full term } \\
\text { newborn infant } \\
\text { (Dubowitz, 1999) }\end{array}$ & - & $13.3 \%$ & - \\
\hline $\begin{array}{l}\text { NOMAS (Palmer, Crawley, \& } \\
\text { Blanco, 1992) }\end{array}$ & $14.3 \%$ & $6.7 \%$ & - \\
\hline \multicolumn{4}{|c|}{$\begin{array}{l}\text { Note. AIMS = Alberta Infant Motor Scale, TIMP }=\text { Infant Motor Performance Scales, MAI= Movement Assessment of } \\
\text { Infant, NNNS = NICU Network Neurobehavioral Scale, NOMAS }=\text { Neonatal Oral Motor Scale, OT = occupational therap- } \\
\text { ist, PT }=\text { physical therapist, SLP }=\text { speech-language therapist, } \%=\text { percentage. }\end{array}$} \\
\hline \multicolumn{4}{|c|}{$\begin{array}{l}\text { This type of evaluation was utilized by } 75 \% \text { of PTs }(15 / 20) \text { in comparison to } 44 \% \text { of OTs }(7 / 16) \text { and } 33 \% \text { of SLP }(2 / 6) \text {. } \\
\text { The total percentage in the PT column is resulting in more than } 100 \% \text { because one professional uses five different } \\
\text { standardized evaluations. }\end{array}$} \\
\hline
\end{tabular}

(5/11) and 0\% of SLP (0/11). All professionals provided services to neonates from a variety of diagnostic categories (Table 1). In addition, professionals indicated that they also provided services to infants with facial malformations, cleft palate anomalies, feeding disorders, and withdrawal from drugs.

Years of experience of the rehabilitation specialists since graduation were similar to the previous survey. Most of the therapists covering NICU were experienced, wherein $64.3 \%$ (27/42 respondents) had more than 10 years of clinical practice (compared to the previous survey: $63 \%, 29 / 46)$ and $4.8 \%(2 / 42)$ had less than 2 years of experience since graduation (compared to the previous survey: 11\%, 5/46). In relation to years of experience working in the NICU setting, the present results showed $35.7 \%(15 / 42)$ had more than 10 years of clinical practice in the NICU setting and $11.9 \%(5 / 42)$ had less than 2 years.

In terms of role, direct services provided by rehabilitation specialists to neonates in the NICU included assessments and direct treatment interventions (PT: 16/20, 80\%; OT: 15/16, 93.7\%; and SLP: 3/6, 50\%), where the remainder of therapists had only a consultant role. Standardized evaluations were utilized by $75 \%$ of PTs $(15 / 20)$ in comparison to $44 \%$ of OTs (7/16) and $33 \%$ of SLPs (2/6). This result is in contrast with the results of the previous survey that demonstrated standardized evaluations were used by fewer professionals (PT: 7/22, 32\%: OT: 4/21, 19\%; SLP: 1/5, 20\%). Table 2 shows the standardized assessments administered by NICU rehabilitation specialists in this present survey.

Therapeutic interventions carried out by OT, PT, and SLP included: handling techniques, environmental interventions, developmental care programs, positioning, neurodevelopmental treatment, splinting, range of motion, sensory integration, feeding, chest physiotherapy, developmental intervention, and family support. The present survey showed that splinting and feeding were more likely to be carried out by OT compared to $\mathrm{PT}$ and that chest physiotherapy and range of motion were performed more by PT than OT. The same relationship between the specificity of intervention conducted by 
Table 3. Comparison Between Surveys of Type of Intervention Performed by Rehabilitation Specialists in the NICU.

\begin{tabular}{|c|c|c|c|c|}
\hline Interventions (\%) surveys & OT & PT & SLP & $p$-value (Fisher Exact test) \\
\hline \multicolumn{5}{|l|}{ Splinting } \\
\hline$(2014)$ & $87.5 \%(14 / 16)$ & $10 \%(2 / 20)$ & $0 \%(0 / 6)$ & .0000 \\
\hline 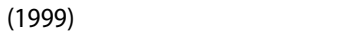 & $90 \%(19 / 21)$ & $33 \%(7 / 21)$ & $0 \%(0 / 5)$ & .0003 \\
\hline \multicolumn{5}{|l|}{ Range of motion } \\
\hline (2014) & $81.3 \%(13 / 16)$ & $100 \%(20 / 20)$ & $0 \%(0 / 6)$ & .0010 \\
\hline (1999) & $48 \%(10 / 21)$ & $100 \%(21 / 21)$ & $0 \%(0 / 5)$ & .0002 \\
\hline \multicolumn{5}{|l|}{ Feeding } \\
\hline$(2014)$ & $100 \%(16 / 16)$ & $15 \%(3 / 20)$ & $50 \%(3 / 6)$ & .0000 \\
\hline (1999) & $100 \%(21 / 21)$ & $29 \%(6 / 21)$ & $80 \%(4 / 5)$ & .0001 \\
\hline \multicolumn{5}{|l|}{ Chest PT } \\
\hline (2014) & $0 \%(0 / 16)$ & $65 \%(13 / 20)$ & $16.7 \%(1 / 6)$ & .0000 \\
\hline$(1999)$ & $5 \%(1 / 21)$ & $67 \%(16 / 21)$ & $20 \%(1 / 5)$ & .0001 \\
\hline \multicolumn{5}{|l|}{ Neurodevelopmental treatment } \\
\hline (2014) & $62.5 \%(10 / 16)$ & $70 \%(14 / 20)$ & $33.3 \%(2 / 6)$ & NS \\
\hline 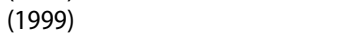 & $62 \%(13 / 21)$ & $81 \%(17 / 21)$ & $0 \%(0 / 5)$ & NS \\
\hline \multicolumn{5}{|l|}{ Sensory integration } \\
\hline (2014) & $50 \%(8 / 16)$ & $20 \%(4 / 20)$ & $33.3 \%(2 / 6)$ & NS \\
\hline 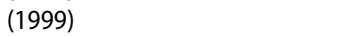 & $52 \%(11 / 21)$ & $38 \%(8 / 21)$ & $20 \%(1 / 5)$ & NS \\
\hline \multicolumn{5}{|l|}{ Developmental interventions } \\
\hline (2014) & $100 \%(16 / 16)$ & $95 \%(19 / 20)$ & $50 \%(3 / 6)$ & NS \\
\hline 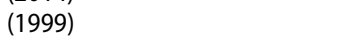 & $90 \%(19 / 21)$ & $67 \%(16 / 21)$ & $40 \%(2 / 5)$ & NS \\
\hline $\begin{array}{l}\text { Individualized developmental } \\
\text { care (2014) }\end{array}$ & $81.3 \%(13 / 16)$ & $90 \%(18 / 20)$ & $66.7 \%(4 / 6)$ & NS \\
\hline (1999) & $90 \%(19 / 21)$ & $67 \%(16 / 21)$ & $40 \%(2 / 5)$ & NS \\
\hline \multicolumn{5}{|l|}{ Positioning } \\
\hline (2014) & $81.3 \%(13 / 16)$ & $100 \%(20 / 20)$ & $66.7 \%(4 / 6)$ & NS \\
\hline 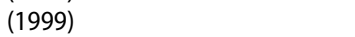 & $95 \%(20 / 21)$ & $86 \%(18 / 21)$ & $0 \%(0 / 5)$ & NS \\
\hline \multicolumn{5}{|l|}{ Environmental modifications } \\
\hline (2014) & $75 \%(12 / 16)$ & $75 \%(15 / 20)$ & $83.3 \%(5 / 6)$ & NS \\
\hline (1999) & $86 \%(18 / 21)$ & $62 \%(13 / 21)$ & $60 \%(3 / 5)$ & NS \\
\hline \multicolumn{5}{|l|}{ Handling } \\
\hline$(2014)$ & $81.3 \%(13 / 16)$ & $90 \%(18 / 20)$ & $33.3 \%(2 / 6)$ & NS \\
\hline 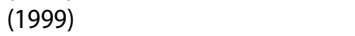 & $86 \%(18 / 21)$ & $86 \%(18 / 21)$ & $20 \%(1 / 5)$ & NS \\
\hline \multicolumn{5}{|l|}{ Family support } \\
\hline (2014) & $87.5 \%(14 / 16)$ & $85 \%(17 / 20)$ & $83.3 \%(5 / 6)$ & NS \\
\hline (1999) & $100 \%(21 / 21)$ & $100 \%(21 / 21)$ & $60 \%(3 / 5)$ & NS \\
\hline
\end{tabular}

Note. $\mathrm{OT}=$ occupational therapist, $\mathrm{PT}=$ physical therapist, $\mathrm{SLP}=$ speech-language therapist, $\mathrm{NS}=$ not significant, $p$-value $=\geq .05$.

OT as compared to PT was consistent with the previous survey (Table 3). The number of SLPs working in the NICU was not sufficient to make this comparison.

As in the previous survey, the present results demonstrated that the rehabilitation professionals $(85.7 \%, 36 / 42)$ were often involved in case discussions with the NICU team regarding future treatment planning. Therapists most commonly provided input on the following: (1) the need for further diagnostic investigations such as video fluoroscopy and imaging $(71.4 \%, 30 / 42)$; (2) recommendations for referral to other services such as neurology and other rehabilitation services $(97.6 \%, 41 / 42)$; and (3) discharge planning to include follow-up rehabilitation services $(97.6 \%, 41 / 42)$. In terms of ethical discussions such as decisions to terminate life support and options for palliative treatment, the rehabilitation specialists were consulted more than previously $(97.6 \%, 41 / 42$; Table 4).

\section{Educational and research activities}

Most therapists $(71.4 \%, 30 / 42)$ were involved in continuing education activities (OT: 87.5\%, 14/16; PT: 70\%, 14/20; and SLP: 33.3\%, 2/6). Topics typically included 
Table 4. Involvement of rehabilitation specialists in case management discussions.

\begin{tabular}{lrrr}
\hline Case management (\%) & \multicolumn{1}{c}{ OT } & PT & SLP \\
\hline Case discussion & & & \\
$(2014)$ & $86,6 \%(13 / 15)$ & $90 \%(18 / 20)$ & $83,3 \%(5 / 6)$ \\
$(1999)$ & $86 \%(18 / 21)$ & $86 \%(19 / 22$ & $80 \%(4 / 5)$ \\
Diagnostic investigations & & $60 \%(12 / 20)$ & $83,3 \%(5 / 6)$ \\
$(2014)$ & $86,6 \%(13 / 15)$ & $55 \%(12 / 22)$ & $80 \%(4 / 5)$ \\
$(1999)$ & $76 \%(16 / 21)$ & & \\
Referrals to other services & & $95 \%(19 / 20)$ & $83,3 \%(5 / 6)$ \\
$(2014)$ & $93,3 \%(14 / 15)$ & $82 \%(18 / 22)$ & $80 \%(4 / 5)$ \\
$(1999)$ & $86 \%(18 / 21)$ & $45 \%(9 / 20)$ & $50 \%(3 / 6)$ \\
Ethical issues & & $36 \%(8 / 22)$ & $20 \%(1 / 5)$ \\
$(2014)$ & $40 \%(6 / 15)$ & & \\
$(1999)$ & $62 \%(13 / 21)$ & $85 \%(17 / 20)$ & $50 \%(3 / 6)$ \\
Discharge planning & & $77 \%(17 / 22)$ & $80 \%(4 / 5)$ \\
$(2014)$ & $93,3 \%(14 / 15)$ & $86 \%(18 / 21)$ & \\
$(1999)$ & & & \\
\hline
\end{tabular}

$\mathrm{OT}=$ occupational therapist; PT = physical therapist; $\mathrm{SLP}=$ speech language therapis ; $\%=$ percentage.

Note. 1 OT did not respond to questions on case management discussions

Table 5. Involvement of Rehabilitation Specialists in Educational Activities.

\begin{tabular}{lcrr}
\hline Education (\%) & \multicolumn{1}{c}{ OT } & \multicolumn{1}{c}{ PT } \\
\hline Families (1999) & $100 \%(20 / 20)$ & $95 \%(20 / 21)$ & $80 \%(4 / 5)$ \\
(2014) & $100 \%(16 / 16)$ & $100 \%(20 / 20)$ & $100 \%(6 / 6)$ \\
Formal lectures (1999) & $35 \%(7 / 20)$ & $30 \%(6 / 20)$ & $50 \%(2 / 4)$ \\
(2014) & $57.1 \%(8 / 14)$ & $40 \%(8 / 20)$ & $50 \%(3 / 6)$ \\
Nursing staff (1999) & $100 \%(20 / 20)$ & $95 \%(20 / 21)$ & $80 \%(4 / 5)$ \\
(2014) & $100 \%(16 / 16)$ & $100 \%(20 / 20)$ & $100 \%(6 / 6)$ \\
Formal lectures (1999) & $55 \%(11 / 20)$ & $60 \%(12 / 20)$ & $50 \%(2 / 4)$ \\
(2014) & $78.5 \%(11 / 14)$ & $80 \%(16 / 20)$ & $0 \%(0 / 6)$ \\
Rehabilitation trainees (1999) & $100 \%(20 / 20)$ & $71 \%(15 / 21)$ & $40 \%(2 / 5)$ \\
(2014) & $100 \%(16 / 16)$ & $90 \%(18 / 20)$ & $100 \%(6 / 6)$ \\
Formal lectures (1999) & & & \\
(2014) & $64.2 \%(9 / 14)$ & $50 \%(10 / 20)$ & $16.6 \%(1 / 6)$ \\
Medical residents (1999) & $75 \%(15 / 20)$ & $80 \%(4 / 5)$ \\
(2014) & $93.7 \%(15 / 16)$ & $65 \%(13 / 20)$ & $83.3 \%(5 / 6)$ \\
Formal lectures (1999) & $47 \%(7 / 15)$ & $43 \%(6 / 14)$ & $50 \%(2 / 4)$ \\
(2014) & $35.7 \%(5 / 14)$ & $25 \%(5 / 20)$ & $0 \%(0 / 6)$ \\
Medical staff (1999) & $65 \%(13 / 20)$ & $52 \%(11 / 21)$ & $80 \%(4 / 5)$ \\
(2014) & $68.7 \%(11 / 16)$ & $75 \%(15 / 20)$ & $83.3 \%(5 / 6)$ \\
Formal lectures (1999) & $54 \%(7 / 13)$ & $45 \%(5 / 11)$ & $50 \%(2 / 4)$ \\
(2014) & $35.7 \%(5 / 14)$ & $40 \%(8 / 20)$ & $0 \%(0 / 6)$ \\
\hline
\end{tabular}

Note. OT = occupational therapist, $\mathrm{PT}=$ physical therapist, $\mathrm{SLP}=$ speech-language therapist, $\%=$ percentage.

Two OTs did not respond to questions on formal lectures.

developmental care and standardized assessments. Rehabilitation specialists provided education to other professional staff in the NICU (medical staff, residents, rehabilitation trainees, and nurses) and to families. This was delivered both formally (e.g. lecture format) or informally (see Table 5). SLPs were not as involved in formal educational activities for nursing, residents, and medical staff as they had been in the previous survey (50\%, 2/4 in 1999 compared to $0 \%, 0 / 6$ in 2014).

There was an increase in participation in research by OT and SLP compared to the previous survey (OT: 7/21, 33\% and SLP: 0/4, 0\%) and a decrease for PT (6/21, 29\%). Half of OT $(8 / 16,50 \%)$ and SLP $(3 / 6,50 \%)$ were involved in research activities compared to $20 \%$ of PT $(4 / 20)$. In research activities, the role of the principal investigator was more frequently taken by SLP ( $2 / 3$ participating in research), while OT were 
collaborators (7/8 participating in research) and PT were evaluators (3/4 participating in research). As in the previous survey, none of the practicing therapists reported authorship in peer-reviewed publications.

\section{Personal perceptions of practice changes}

In the present survey, all respondents were asked one open-ended question about their opinion as to what had changed most over the last decade in their role in the NICU. The responses were categorized into four themes: (1) education; (2) collaboration/discussion; (3) modifications in interventions; and (4) same professional role as 15 years ago. The majority $(64 \%, 27 / 42)$ of therapists surveyed reported that there had been important modifications in care provision (e.g. use of evidence-based interventions) over the past decade. These respondents reported that the present focus of intervention was on family-centered developmental care rather than more specific impairmentfocused interventions such as chest/respiratory care. Furthermore, therapists (19\%, 8/42) believed that the service delivery in tertiary health care had become more consultative and preventative. Only $4.8 \%$ (2/42) of respondents felt that the education initiatives, for example, education to parents about feeding, had changed. A small subset $(9.5 \%, 4 / 42)$ felt there were few changes over the past 10 years. One respondent $(2.4 \%, 1 / 42)$ did not respond to this question.

\section{Discussion}

Over the last two decades, the Canadian health system has experienced an increase in NICU beds due to the increase in birth rates in the number of infants with low birth weight $(\leq 2.500 \mathrm{~g})$, survival rates of infants born preterm, and infants born late preterm (CANSIM, 2013). This trend was reflected in the comparison of results of the present survey with the previous survey (Limperopoulos \& Majnemer, 2002). With an increased number of beds in Canadian NICUs, more rehabilitation specialists provide care assistance including SLP. Most rehabilitation specialists described important modifications in care provision, to include additional coverage by various rehabilitation specialists in the NICUs. It is difficult to know whether this is simply due to increasing demand (larger numbers of neonates with greater complexity of illness) and/or greater recognition of the value of rehabilitation assessments and interventions. It is also possible that in addition to OTs and PTs, SLPs in Canada are receiving more training in the assessment and treatment of neonates at high risk. It is likely a combination of all of these elements; however this cross-sectional study cannot ascertain this.

Results of the present survey suggest that the main role of rehabilitation specialists in the NICU was still prioritized to direct clinical intervention, that is, assessment and treatment. In the last decade, studies have developed and described a variety of standardized assessment tools and their importance in the context of developmental care support in NICU (Atun-Einy \& Scher, 2008; Byrne \& Campbell, 2013; Majnemer \& Snider, 2005). Physical examination and objective assessment are competencies required by OT, PT, and SLP working in the NICU setting. Continuous examination and monitoring of the infant during each contact in the NICU is fundamental to evaluate whether the 
infant is improving or deteriorating in terms of their motor, behavioral, and physiological state (Altimier \& Phillips, 2013; Sweeney et al., 2009). The present survey results are consistent in demonstrating an increase in the utilization of standardized assessments. The one assessment that is used by both OTs and PTs was the TIMP, which measures the construct of postural control during everyday activities such as bathing, dressing, and play. The interpretation of the results of the TIMP to parents would be an important component of care.

Allinson, Doyle, Denehy, and Spittle (2017) conducted a survey in Australia and New Zealand of special care nurseries and also NICUs $(n=26$ in this latter group) with a focus on the type of health professionals providing rehabilitation services to these units, with an overview of their qualifications and experience. A secondary objective was to determine which evaluation tools were used for neurobehavioral assessment. Differences in the health disciplines providing services in the NICU were found such that PT and SLP were more commonly seen in the nurseries, which differ from the predominance of OT's role in Canada. This may relate to the differing approaches to neonatal feeding intervention between the two countries. While the Australian rehabilitation specialists were likely to perform standardized neurologic or neurobehavioral assessments in their NICUs, the primary standardized assessment of choice was Prechtl's General Movements Assessment. This gestalt qualitative assessment of spontaneous infant movements does not provide a functional interpretation of postural control as it relates to everyday activities and thus cannot contribute to treatment planning.

Although rehabilitation specialists have become more aware of the knowledge to practice gaps and may be implementing strategies to address these gaps in local settings (Menon, Korner-Bitensky, Kastner, McKibbon, \& Straus, 2009), integrating research into practice remains challenging. Although a subset reported being involved in research, they did not report any publications, suggesting that involvement may be more as a collaborator at this time. This highlights the need for infrastructure support to enable clinicians to engage more actively in research projects.

The changing role of the parent has been an important development in the evolution of care in the NICU. Substantial scientific evidence articulating the importance of family-centered care to include long-term hospitalizations has been reported (Arango, 2011). Family-centered care is an evidence-based philosophy of care in which the main objective is the partnership between health professionals and families. Parents are considered central to the infant's care (Barbosa, 2013). Basic concepts are as follows: family collaboration, family participation, dignity and respect, and sharing information (Griffin, 2006). Further, Altimier and Phillips (2013) described an integrative developmental care model using neuroprotective interventions to promote healthy development and to prevent disabilities in premature infants in NICU. The seven core measures for family centered-development care involve minimizing stress and pain, protecting skin, optimizing nutrition, providing a healing environment, partnering with families, and optimizing positioning and handling. Of particular interest to rehabilitation specialists, the greater involvement of families was the focus of the NICU care path for physical therapists and the NICU discharge path for parents (Byrne \& Campbell, 2013; Garber, 2013; Goldstein, 2013). The current survey demonstrates that adoption of a supportive family-centered approach, in the context of the NICU environment, already evident in 
our initial survey, was not significantly different. However, the manner in which this approach was implemented (e.g. responsiveness to family needs, shared decision-making, level of collaboration, and knowledge sharing) was not ascertained. Thus, the current study cannot rule out differences in the quality and authenticity of family-centered care now being provided in the nurseries. This approach is challenging to execute in the context of the NICU environment, but nonetheless important for child and family well-being (Ramezani, Shirazi, Saverstan, \& Moattari, 2014).

The results of the present survey suggest an increase in participation rates of the rehabilitation specialists, in particular SLP, in family education, as compared to the previous survey. Therapists seem to have become more focused on promoting the involvement of parents in the care of their infants as well as in supporting the development of greater confidence and competence in parenting skills in the challenging NICU environment. However, because of the low sample in the present study, this observation would need to be validated in future studies.

Introduction of new practices in the NICU may have been augmented through greater opportunities for advancing training (e.g. continuing professional development at workshops or conferences) of rehabilitation specialists. It is also conceivable that there is greater emphasis on parent education over the last decade (Sweeney, Heriza, Blanchard, \& Dusing, 2010). Although the role of rehabilitation specialists in the NICU has expanded since the first survey, rehabilitation specialists maintain an important primary clinical role in the NICU. There has been an increased use of standardized evaluations and utilization of evidence-based interventions such as individualized developmental care, feeding support, and a shift away from respiratory care. Neurodevelopmental treatment (i.e. Bobath) remained a therapeutic strategy for a subset, although rigorous scientific evidence more strongly supports other interventions such as neonatal developmental care (Newborn Individualized Developmental Care and Assessment Program (NIDCAP); Butler \& Darrah, 2001; Garber, 2013; Montirosso, Del Prete, Bellù, Tronick, \& Borgatti, 2012; Vaughan-Graham, Cott, \& Wright, 2015; Vergara et al, 2006). This survey was not designed to identify the reasons for the changes noted over time in the delivery of rehabilitation services in the NICU. This is one of the limitations of this study.

This study had several other limitations. The findings of a survey reflect the personal perspectives and perceptions of the individual therapists, and may not be accurate depictions of their service provision. Nonetheless, the survey itself was consistent for the two time points. Therefore, we were able to compare changing perspectives over time. Furthermore, the questions asked were quite specific and designed to clearly describe the services being provided on a regular basis. In our questionnaire, we asked if particular therapeutic interventions were used by the rehabilitation specialists. An important limitation was that we did not determine the extent or quality to which evidence-based assessments or interventions were used. An important next step in this investigation would be to describe how the assessments and therapeutic interventions are being conducted; on whom, for what purpose, and how often. Another limitation was the small number of SLP who responded to the questionnaire. This likely reflects the more limited role of these health professionals in Canadian NICUs, and may be different in other countries. 
Future studies should be directed not only at objectively monitoring the change in practice profile over time, but should also apply mixed methods (qualitative and quantitative) to better understand the key drivers to change that may be personal, educational, and/or institutional. This will guide strategies to enhance the uptake of practice guidelines and the best evidence to promote best practices in the NICU.

\section{Conclusion}

In summary, in comparison with results of the previous survey conducted 15 years ago of rehabilitation practices in Canadian NICUs, rehabilitation specialists now have more dedicated time in the NICU. More therapists reported using standardized measures and interventions that are supported by recent evidence, such as intervention based on family-centered developmental care. These changes in care provision are likely due to greater evidence available for this area of rehabilitation service and the effective translation of that new knowledge into practice in the NICU setting. Ongoing progress in the understanding of factors that influence the outcomes of neonates at risk and evidence on the benefits of new intervention strategies will inevitably continue to support greater involvement and impact of rehabilitation specialists in the care and outcomes of this atrisk population (Maitre, 2015). It is important that these specialized care providers capitalize on new scientific discoveries to optimize the healthy development of newborns born critically ill and the well-being of their families.

\section{Acknowledgements}

We would like to thank all the health professionals and institutions that participated in the survey.

\section{Disclosure statement}

There is no conflict of interest to report.

\section{About the authors}

Zachary Boychuck is a $\mathrm{PhD}$ student in Rehabilitation Science, School of Physcial \& Occupational Therapy, McGill University.

Laurie Snider is Director \& Associate Dean, School of Physical \& Occupational Therapy, McGill University.

Jose Simon Camelo Junior is appointed to the Department of Pediatrics, Ribeirao Preto Medical School University of Sao Paulo, Sao Paulo, Brazil and the Centro Universitario Estacio de Ribeirao Preto, Ribeirão Preto, Brazil.

Pamela Nery PT, PhD was a doctoral exchange student from Department of Pediatrics, Ribeirao Preto Medical School University of Sao Paulo, Sao Paulo, Brazil; Centro Universitario Estacio de Ribeirao Preto, Ribeirao Preto, Brazil.

Jessica Goldschleger and Fatima Khodary were graduate students in Rehabilitation Science, School of Physical \& Occupational Therapy, McGill University at the time of this study.

Dr Annette Majnemer is Professor and Vice-Dean, Education, Faculty of Medicine, McGill University and Senior Investigator, Research Institute, McGill University Health Centre, Montreal, CANADA. 


\section{Funding}

We also wish to thank Coordenação de Aperfeiçoamento de Pessoal e Nível Superior for funding this study under process number 99999.010624/2013-09.

\section{References}

Adams-Chapman, I. (2006). Neurodevelopmental outcome of the late preterm infant. Clinics in Perinatology, 33(4), 947-964.

Aita, M., \& Snider, L. (2003). The art of developmental care in the NICU: A concept analysis. Journal of Advanced Nursing, 41(3), 223-232.

Allinson, L. G., Doyle, L. W., Denehy, L., \& Spittle, A. J. (2017). Survey of neurodevelopmental allied health teams in Australian and New Zealand neonatal nurseries: Staff profile and standardised neurobehavioral/neurological assessment. Journal of Paediatrics and Child Health, 53(6), 578-584.

Als, H., Duffy, F. H., McAnulty, G. B., Rivkin, M. J., Vajapeyam, S., Mulkern, R. V., ... Eichenwald, E. C. (2004). Early experience alters brain function and structure. Pediatrics, 113(4), 846-857.

Als, H., \& McAnulty, G. B. (2011). The newborn individualized developmental care and assessment program (NIDCAP) with kangaroo mother are (KMC): Comprehensive care for preterm infants. Current Women's Health Reviews, 7(3), 288-301.

Altimier, L., \& Phillips, R. M. (2013). The neonatal integrative developmental care model: seven neuroprotective core measures for family-centered developmental care. Newborn and Infant Nursing Reviews, 13(1), 9-22.

American Speech-Language-Hearing Association (ASHA). (2004). Knowledge and skills needed by speech-language pathologists providing services to infants and families in the NICU environment. Leader, 9(8), 159-165.

Amiel-Tison, C. (1968). Neurological evaluation of the maturity of newborn infants. Archives of Disease in Childhood, 43(227), 89-93.

Arango, P. (2011). Family-centered care. Academic Pediatrics, 11(2), 97-99.

Atun-Einy, O., \& Scher, A. (2008). Measuring developmentally appropriate practice in neonatal intensive care units. Journal of Perinatology, 28(3), 218-225.

Barbosa, V. M. (2013). Teamwork in the neonatal intensive care units. Physical and Occupational Therapy in Pediatrics, 33(1), 5-26.

Bayley, N. (1993). Bayley scales of infant development: Manual. San Antonio, TX: Psychological Corporation.

Beck, S., Wojdyla, D., Say, L., Pilar Bertran, A., Meraldi, M., Harris Requejo, J., ... Van Look, P. (2010). The worldwide incidence of preterm birth: A systematic review of maternal mortality and morbidity. Bulletin of the World Health Organization, 88(1), 31-38.

Butler, C., \& Darrah, J. (2001). Effects of neurodevelopmental treatment (NDT) for cerebral palsy: An AACPDM evidence report. Developmental Medicine and Child Neurology, 43 (11), 778-790.

Byrne, E., \& Campbell, S. K. (2013). Physical therapy observation and assessment in the neonatal intensive care unit. Physical and Occupational Therapy in Pediatrics, 33(1), 39-74. doi:10.3109/ 01942638.2012.754827

Campbell, S. K. (2013). Use of care paths to improve patient management. Physical and Occupational Therapy in Pediatrics, 33(1), 27-38. doi:10.3109/01942638.2012.694992

Campbell, S. K., Kolobe, T. H., Osten, E. T., Lenke, M., \& Girolami, G. L. (1995). Construct validity of the test of infant motor performance. Physical Therapy, 75(7), 585-596.

Canadian Socio-Economic Information System (CANSIM) (2013). Population and demography. Retrieved from: http://www.statcan.gc.ca/tables-tableaux/sum-som/

Chandler, S., Andrews, M. S., Swanson, M. V., \& Larson, A. H. (1980). Movement Assessment of Infants: A manual. (Vol. 4631, 53 p.). Washington, MA: Rolling Bay. 
Chiarello, L., \& Effgen, S. K. (2006). Updated competencies for physical therapists working in early intervention. Pediatric Physical Therapy, 18(2), 148-158.

Constantinou, J. C., Adamson-Macedo, E. N., Mirmiran, M., Ariagno, R. L., \& Fleisher, B. E. (2005). Neurobehavioral assessment predicts differential outcome between VLBW and ELBW preterm infants. Journal of Perinatology, 25(12), 788-793.

Darsaklis, V., Snider, L. M., Majnemer, A., \& Mazer, B. (2011). Predictive validity of Prechtl's method on the qualitative assessment of general movements: A systematic review of the evidence. Developmental Medicine \& Child Neurology, 53(10), 896-906.

Dubowitz, L. M. (1999). The neurological assessment of the preterm and full-term newborn infant. (167 p.). Cambridge: University Press.

Fucile, S., Gisel, E. G., Mcfarland, D. H., \& Lau, C. (2011). Oral and non-oral sensorimotor interventions enhance oral feeding performance in preterm infants. Developmental Medicine \& Child Neurology, 53(9), 829-835.

Garber, J. (2013). Oral-motor function and feeding intervention. Physical \& Occupational Therapy in Pediatrics, 33(1), 111-138.

Goldstein, L. A. (2013). Family support and education. Physical \& Occupational Therapy in Pediatrics, 33(1), 139-161.

Griffin, T. (2006). Family-centered care in the NICU. Journal of Perinatal and Neonatal Nursing, 20(1), 98-102.

Harijan, P., Beer, C., Glazebrook, C., Israel, C., Marlow, N., Whitelaw, A., \& Johnson, S. (2012). Predicting developmental outcomes in very preterm infants: Validity of a neonatal neurobehavioral assessment. Acta Paediatrica, 101(7), e275-e281.

King, G., Currie, M., Bartlett, D. J., Strachan, D., Tucker, M. A., \& Willoughby, C. (2008). The development of expertise in paediatric rehabilitation therapists: The roles of motivation, openness to experience, and types of caseload experience. Australian Occupational Therapy Journal, 55(2), 108-122.

Korner, A. F., B. J., Thom, V. A., \& Constantinou, J. C. (2000). The neurobehavioral assessment of the preterm infant revised. (2nd ed.). Van Nuys, CA: Child Development Media.

Legendre, V., Burtner, P. A., Martinez, K. L., \& Crowe, T. K. (2011). The evolving practice of developmental care in the neonatal unit: A systematic review. Physical \& Occupational Therapy in Pediatrics, 31(3), 315-338.

Lester, B. M., \& Tronick, E. Z. (2004). The neonatal intensive care unit network neurobehavioral scale procedures. Pediatrics, 113(Supplement 2), 641-667.

Limperopoulos, C., \& Majnemer, A. (2002). The role of rehabilitation specialists in Canadian NICUs: A national survey. Physical \& Occupational Therapy in Pediatrics, 22(1), 57-72.

Mahoney, M. C., \& Cohen, M. I. (2005). Effectiveness of developmental intervention in the neonatal intensive care unit: Implications for neonatal physical therapy. Pediatric Physical Therapy, 17(3), 194-208.

Maitre, N. (2015). Neuroreabilitation after neonatal intensive care: Evidence and challenges. Archives of Disease in Childhood - Fetal and Neonatal Edition, 100(6), F534-F540.

Majnemer, A., \& Snider, L. (2005). A comparison of developmental assessments of the newborn and young infant. Mental Retardation and Developmental Disabilities Research Reviews, 11(1), 68-73.

Menon, A., Korner-Bitensky, N., Kastner, M., McKibbon, K. A., \& Straus, S. (2009). Strategies for rehabilitation professionals to move evidence-based knowledge into practice: A systematic review. Journal of Rehabilitation Medicine, 41 (13), 1024-1032.

Montirosso, R., Del Prete, A., Bellù, R., Tronick, E., \& Borgatti, R. (2012). Level of NICU quality of developmental care and neurobehavioral performance in very preterm infants. Pediatrics, 129 (5), e1129-e1137.

O'Connor, S., \& Pettigrew, C. M. (2009). The barriers perceived to prevent the successful implementation of evidence-based practice by speech and language therapists. International Journal of Language \& Communication Disorders, 44(6), 1018-1035.

Palmer, M., Crawley, K., \& Blanco, I. (1992). Neonatal oral-motor assessment scale: A reliability study. Journal of Perinatology, 13(1), 28-35. 
Piper, M. C., Pinnell, L. E., Darrah, J., Maguire, T., \& Byrne, P. J. (1991). Construction and validation of the Alberta Infant Motor Scale (AIMS). Canadian Journal of Public Health, 83, S46-S50.

Prechtl, H. F. (2001). General movement assessment as a method of developmental neurology: New paradigms and their consequences. Developmental Medicine and Child Neurology, 43(12), 836-842.

Ramezani, T., Shirazi, Z. H., Saverstan, R. S., \& Moattari, M. (2014). Family-centered care in neonatal intensive care unit: A concept analysis. International Journal Community Based Nursing and Midwifery, 2 (4), 268-278.

Rossetti, L. M. (1990). The Rossetti Infant-Toddler Language Scale: A measure of communication and interaction. East Moline, IL: LinguiSystems.

Snider, L., Majnemer, A., Mazer, B., Campbell, S., \& Bos, A. F. (2008). A comparison of the general movements assessment with traditional approaches to newborn and infant assessment: Concurrent validity. Early Human Development, 84(5), 297-303.

Sweeney, J. K., Heriza, C. B., Blanchard, Y., \& Dusing, S. C (2009). Neonatal physical therapy. Part I: Clinical competencies and neonatal intensive care unit clinical training models. Pediatric Physical Therapy, 21(4), 296-307.

Sweeney, J. K., Heriza, C. B., Blanchard, Y., \& Dusing, S. C. (2010). Neonatal physical therapy. Part II: Practices frameworks and evidence-based practice guidelines. Pediatric Physical Therapy, 22(1), 2-16.

Symington, A. J., \& Pinelli, J. (2006). Developmental care for promoting development and preventing morbidity in preterm infants. Cochrane Database of Systematic Review, 2003(4), CD001814.

Vaughan-Graham, J., Cott, C., \& Wright, F. V. (2015). The Bobath (NDT) concept in adult neurological rehabilitation: What is the state of knowledge? A scoping review. Part I: Conceptual perspective. Disability and Rehabilitation, 37 (20), 1793-1807.

Vergara, E., Anzalone, M., Bigsby, R., Gorga, D., Holloway, E., Hunter, J., Laadt G., \& Strzyzewski, S. (2006). Specialized knowledge and skills for occupational therapy practice in the neonatal intensive care unit. American Journal of Occupational Therapy, 60(6), 659-668. 